\title{
Lusioersily
}

\section{A systematic review of school-based physical activity interventions on children's wellbeing}

Rafferty, R., Breslin, G., Brennan, D., \& Hassan, D. (2016). A systematic review of school-based physical activity interventions on children's wellbeing. International Review of Sport and Exercise Psychology, 9(1), 215-230. https://doi.org/10.1080/1750984X.2016.1164228

Link to publication record in Ulster University Research Portal

\section{Published in:}

International Review of Sport and Exercise Psychology

\section{Publication Status:}

Published online: 17/05/2016

DOI:

10.1080/1750984X.2016.1164228

\section{Document Version}

Publisher's PDF, also known as Version of record

\section{General rights}

Copyright for the publications made accessible via Ulster University's Research Portal is retained by the author(s) and / or other copyright owners and it is a condition of accessing these publications that users recognise and abide by the legal requirements associated with these rights.

\section{Take down policy}

The Research Portal is Ulster University's institutional repository that provides access to Ulster's research outputs. Every effort has been made to ensure that content in the Research Portal does not infringe any person's rights, or applicable UK laws. If you discover content in the Research Portal that you believe breaches copyright or violates any law, please contact pure-support@ulster.ac.uk. 


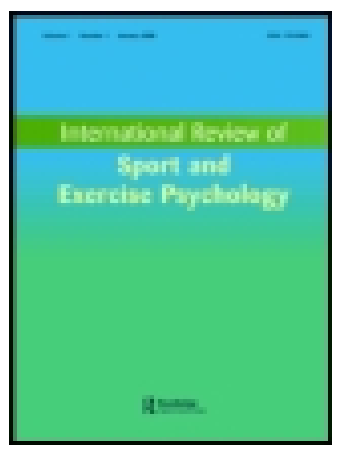

International Review of Sport and Exercise Psychology

\section{A systematic review of school-based physical activity interventions on children's wellbeing}

\section{Ruth Rafferty, Gavin Breslin, Deirdre Brennan \& David Hassan}

To cite this article: Ruth Rafferty, Gavin Breslin, Deirdre Brennan \& David Hassan (2016): A systematic review of school-based physical activity interventions on children's wellbeing, International Review of Sport and Exercise Psychology, DOI: 10.1080/1750984X.2016.1164228

To link to this article: http://dx.doi.org/10.1080/1750984X.2016.1164228

\section{冓 Published online: 17 May 2016.}

Submit your article to this journal

Q View related articles $₫$

View Crossmark data $\nearrow$ 
REVIEW ARTICLE

\title{
A systematic review of school-based physical activity interventions on children's wellbeing
}

\author{
Ruth Rafferty, Gavin Breslin, Deirdre Brennan and David Hassan \\ Sport and Exercise Science Research Institute, Ulster University Jordanstown Campus, Newtownabbey, \\ Northern Ireland
}

\begin{abstract}
Purpose: The aim of this study was to review the effect of schoolbased physical activity interventions on children's wellbeing.

Method: A systematic search of school-based physical activity studies was conducted using EBSCOhost Psyclnfo, EBSCOhost Medline and Web of Science. Initially 995 studies were retrieved and, following the removal of duplicates, the titles and abstracts of 984 studies were screened. This screening identified 53 relevant studies from which 42 were excluded, resulting in 11 articles being reviewed.

Results: Three studies reported a positive increase in wellbeing; however, only one of those studies also significantly increased physical activity. It was apparent that the measurement of wellbeing and physical activity was inconsistent across studies, making conclusions difficult to draw. The wellbeing measures used neglected to account for the children's perspectives of wellbeing.

Conclusions: The effect of a physical activity intervention on increasing wellbeing appears to be more complex than originally believed. The complexity may in part be due to methodological issues and the choice of wellbeing and physical activity measurement. We recommend that future physical activity interventions include a measure of wellbeing developed from the child's perspective, and that future reviews narrow the search to only interventions that have had success at increasing physical activity before exploring effects on wellbeing.
\end{abstract}

\section{ARTICLE HISTORY}

Received 23 October 2014

Accepted 7 March 2016

\section{KEYWORDS}

Quality of life; intervention; health promotion; education; public health

\section{Introduction}

Wellbeing is considered an important aspect of health to individuals and to society (World Health Organisation, 2006) with the United Kingdom (UK) Government including wellbeing as a marker of health within the nation (Cameron, 2010). Children in the United Kingdom (UK) have lower levels of wellbeing than many of their peers in other developed countries, after being positioned 14th out of 29 countries (United Nations International Children's Emergency Fund, UNICEF, 2013). The consequences of lower levels of wellbeing are broad, including associations with poor mental health, involvement in risky behaviour and social isolation among others (Friedli, 2009; Rees, Bradshaw, Goswami, \& Keung, 2010). 
Furthermore, the absence of negative symptoms of wellbeing may not equate to the presence of positive wellbeing, such as happiness and life satisfaction (Huppert \& Whittington, 2003). A positive wellbeing may provide additional benefits, such as reducing the onset of mental health disorders (Park, 2004), enhancing relationships with others (Friedli, 2009; Rees et al., 2010) or greater attainment in education (Rees et al., 2010). Therefore, when determining one's wellbeing, it is important to consider both the positive and negative dimensions of wellbeing. Although there is no universally accepted definition of child wellbeing (Pollard \& Lee, 2003), the most recognised definition proposed by Diener (1984) incorporates subjective evaluations of psychological, physical and social health implying that wellbeing is multidimensional (Pollard \& Lee, 2003). Considering the broad nature of wellbeing, it is unsurprising that a myriad of factors potentially influence a child's wellbeing such as gender, socioeconomic status, weight status (Hartmann, Zahner, \& Puhse, 2010) and physical activity (Biddle, Fox, \& Boutcher, 2000). Physical activity is the focus of this review.

Physical activity is defined as any bodily movement produced by skeletal muscles that require energy expenditure (Casperson, Powell, \& Christenson, 1985). In children, the promotion of physical activity is considered a public health priority as children are insufficiently active. Data from five European countries reported that only $4.6 \%$ of girls and $16.8 \%$ of boys aged $10-12$ years met the moderate to vigorous intensity physical activity (MVPA) guidelines for health (Verloigne et al., 2012). Yet children who reported high levels of physical activity scored lower in depression (Cheung, Mak, \& Chan, 2008; Parfitt, Pavey, \& Rowlands, 2009; Tomson, Pangrazi, Friedman, \& Hutchinson, 2003) and anxiety (Parfitt et al., 2009) but higher in vigour (Cheung et al., 2008), physical self-worth (Parfitt et al., 2009) and global self-esteem (Parfitt \& Eston, 2005), as well as a better quality of life (Sanchez-Lopez et al., 2009). Furthermore, those who met the recommended daily physical activity guidelines for health of at least 60 minutes of MVPA each day (Department of Health, Physical Activity, Health Improvement and Protection, 2011) scored higher on measures of wellbeing than less active children (Breslin et al., 2012). Beneficial effects of physical activity interventions on wellbeing in children have been reported with a small effect size in favour of physical activity reducing depression and anxiety (Larun, Nordheim, Ekeland, Hagen, \& Heian, 2006) and a moderate effect size showing increases in self-esteem, at least in the short term (Ekeland, Heian, \& Hagen, 2005). Therefore, continued promotion of physical activity is needed to increase children's activity levels for health benefits.

Despite the beneficial effects of physical activity interventions on children's wellbeing, the evidence for children is not as convincing as it is for adults, potentially because the few interventions that have been conducted have low methodological quality research designs (Biddle \& Asare, 2011) and measurement limitations (Parfitt \& Eston, 2005). A systematic review of child wellbeing found that wellbeing was inconsistently measured, was narrowly focused and used mainly negative indicators (Pollard \& Lee, 2003). Yet the definition of wellbeing implies that it is a multidimensional concept that encompasses both positive and negative indicators (Pollard \& Lee, 2003). Equally, self-report measures of physical activity have been widely used in children's physical activity as they are easy to administer and low in cost (Biddle, O'Connell, \& Braithwaite, 2011). However, self-report measures cannot accurately assess every bout of activity engaged in because children are likely to have difficulty recalling their physical activity from the previous week due to a less developed cognitive ability than adults (Chinapaw, Mokkink, van Poppel, van Mechelen, \& Terwee, 2010). In order to overcome the limitations of self-report, objective 
measures of physical activity have been utilised, with accelerometers being the most precise measurement tool for children's activity (Mattocks et al., 2008). Based on these observations, one aim of this review is to consider the measurement of wellbeing and physical activity in intervention studies to provide recommendations when selecting an appropriate measurement tool.

School-based settings are considered ideal for targeting children's health as they provide access to a large number of children across broad socioeconomic strata without having to discriminate or stigmatise (Fox, Cooper, \& McKenna, 2004) and with less chance of poor adherence to the intervention programme (Harris, Kuramoto, Schulzer, \& Retallack, 2009). Many school-based physical activity intervention programmes have shown success at increasing physical activity, as evidenced by a review by Kriemler et al. (2011), whereby all 16 intervention trials reported an increase in physical activity either in school or out of school or in nine out of 10 studies for overall physical activity. These results indicate that school-based physical activity promotion is an effective strategy to increase physical activity levels in children.

In contrast, reviews of school-based interventions on children's wellbeing have reported mixed findings. Van Wijnen, Wendel-Vos, Wammes, and Bemelmans (2009) investigated the extent to which psychosocial wellbeing was affected by school-based obesity prevention programmes of children and adolescents with the rationale being that some psychosocial problems have been correlated with obesity/overweight and that interventions aiming to reduce body weight may show positive effects on psychosocial wellbeing (van Wijnen et al., 2009). No firm conclusions could be derived due to the small number of studies found, and the wellbeing measures used differed between studies, making comparison difficult. In contrast, a meta-analysis found, when analysing different settings of physical activity interventions and their effect on child mental health, that school-based interventions had the greatest effect on mental health in children aged 3-18 years (Ahn \& Fedewa, 2011). However, the interventions reviewed in van Wijnen et al. (2009) targeted obesity prevention/ reduction, and hence they did not have to include physical activity. Moreover, no previous reviews considered whether school-based interventions significantly increased physical activity and consequently what effect this had on wellbeing. It seems important to consider whether the intervention significantly increased physical activity in order to determine what effect increased activity levels have on children's wellbeing. Hence, the current review investigated the effect of school-based physical activity interventions on the physical activity levels and wellbeing of children, which had not previously been investigated.

The primary aim of this review was to determine the effect of school-based physical activity interventions on children's physical activity levels and their wellbeing. Secondly, the review also took the measurement of wellbeing and physical activity into consideration by highlighting the methodological importance of choosing a suitable, valid and reliable measure of both variables for future studies.

\section{Method}

\section{Search strategy}

This systematic review follows the search strategy as recommended by the Preferred Reporting Items for Systematic Reviews and Meta-Analyses (PRISMA) guidelines (Moher et al., 
Table 1. Categories and search terms for the literature search.

\begin{tabular}{ll}
\hline Category & \multicolumn{1}{c}{ Search terms } \\
\hline $\begin{array}{l}\text { Population } \\
\text { Setting }\end{array}$ & $\begin{array}{l}\text { Child; student; pupil; boy; girl } \\
\text { Method of treatment }\end{array}$ \\
$\begin{array}{l}\text { Primary school; elementary school; middle school } \\
\text { Physical activity; exercise; fitness; sport; physical education; aerobic exercise; training; lifestyle; } \\
\text { Objective of treatment } \\
\text { walk; intervention; school based intervention; programme; experiment; education; evaluation } \\
\text { Well-being; wellbeing; quality of life; wellness; psychological wellbeing; happiness; life } \\
\text { satisfaction; self-esteem; self-concept; body image; physical appearance; anxiety; depression }\end{array}$ \\
\hline
\end{tabular}

2015). A systematic search was carried out in January 2016 in the following databases: EBSCOhost Psyclnfo, EBSCOhost Medline and Web of Science. Each database was searched from the year of their inception to January 2016. The search used relevant indexing and text words of the search terms, adjusting for each database. Table 1 shows the categories and search terms used for the literature search. Wellbeing is considered a complex and multidimensional concept that encompasses both positive and negative indicators (Pollard \& Lee, 2003) and could be defined by the inclusion of a broad range of constructs, including many mental health disorders, behaviour problems, symptoms of depression, anxiety, life satisfaction and happiness among others. However, it is not feasible to conduct a review of such broad magnitude. Therefore, for the purposes of this review, wellbeing was defined based on the variables of wellbeing listed in Table 1. These included the most widely measured variables of wellbeing in physical activity and wellbeing studies in children that is, depression and anxiety (Biddle $\&$ Asare, 2011), which represented negative indicators in the search strategy, while the search terms used in a review of child wellbeing represented the positive indicators of wellbeing (Pollard \& Lee, 2003). Body image and physical appearance were also included. The physical activity search terms utilised were similar to those used in a previous review of school-based physical activity interventions (Kriemler et al., 2011). In an attempt to ensure that articles using slightly different search terms for each category were not omitted, the search terms included various suffixes and synonyms of these terms. Initially, articles were screened based on the content of the title and abstract and assessed for their relevancy. The full text of potentially suitable articles were retrieved. Reference lists of review studies and retrieved articles were scanned for additional articles. All identified articles were reviewed in detail based on the inclusion/exclusion criteria. The first author selected the studies. If there was any uncertainty regarding selection criteria, then the second author was consulted.

\section{Criteria for inclusion/exclusion}

The eligibility of the studies for inclusion was assessed using the following criteria: (a) must include physical activity as a component of the intervention; (b) the intervention is school based; (c) participants were aged 6-12 years old (preadolescent); (d) wellbeing and physical activity of children is reported pre and post intervention; (e) the studies are of quantitative research using an experimental/quasi-experimental design; ( $f$ ) published peer reviewed articles only; and (g) articles published in the English language. The exclusion criteria include (a) studies that investigate specific populations, such as persons with physical or mental disabilities, children with critical illness, eating disorders, asthma, diabetes or mental disorders and studies focusing specifically on treatment of obese children in clinical settings; (b) interventions that are family or community based. 


\section{Risk of bias assessment}

Studies were assessed for risk of bias using criteria from the Cochrane Handbook for Systematic Reviews of Interventions (Version 5.1.0; Higgins, Altman, \& Sterne, 2011). The criteria include six domains from which an estimation of the risk of bias for each domain was given for each study included in the review. The six domains include selection bias (random sequence generation, allocation concealment), performance bias (blinding of participants and personnel), detection bias (blinding of outcome assessment), attrition bias (incomplete outcome data), reporting bias (selective reporting) and other sources of bias.

\section{Characteristics of the selected intervention studies}

A detailed extraction of relevant information from each of the selected studies was conducted. The information retrieved included the authors, the study design, the sample size and age, the duration and frequency of the intervention and a description of the intervention. The measurements retrieved were: the indicator(s) of wellbeing and physical activity and the corresponding measurement tools used, and whether or not the intervention had a significant effect on physical activity levels and the wellbeing indicator(s).

\section{Results}

The search strategy identified 995 studies (109 from Medline; 67 from Psychlnfo; 816 from Web of Science and three from a hand search of reference lists from review studies and retrieved studies; see Figure 1). After the removal of duplicates $(n=11)$, the titles and abstracts of 984 studies were screened. This screening identified 53 relevant studies, which were obtained as full text articles. Consequently, the full text of 53 studies was screened in detail using the pre-established inclusion criteria of the review.

From the 53 studies, 42 were excluded based on the following criteria: Ten studies did not measure a construct of wellbeing relevant to this review (as listed in Table 1), four studies were study protocols, four studies were not school-based, four studies had no physical activity in the intervention, 13 studies did not measure physical activity, three studies were qualitative, three studies were cross-sectional in design and one study was a quasi-experimental time series and measured wellbeing of different children once a year over 6 years, hence did not include pre and post measures of wellbeing. Finally, 11 studies were identified that met the inclusion criteria.

\section{Risk of bias assessment}

The estimated risk of bias of each of the interventions included in our review is summarised in Table 2. In general, the risk of bias was high in studies based on random sequence generation, concealment and blinding of the intervention condition of participants and personnel involved. Although six of the 11 studies were randomised controlled trials (RCTs), only four studies described the process of randomisation (Ha et al., 2015; Hartmann et al., 2010; Meyer et al., 2014; Sahota et al., 2001). Across the domains, five studies had the highest risk of bias. In general, a low risk of bias appeared to be more frequent on the selective outcome reporting, the outcome of incomplete data and the risk of other 


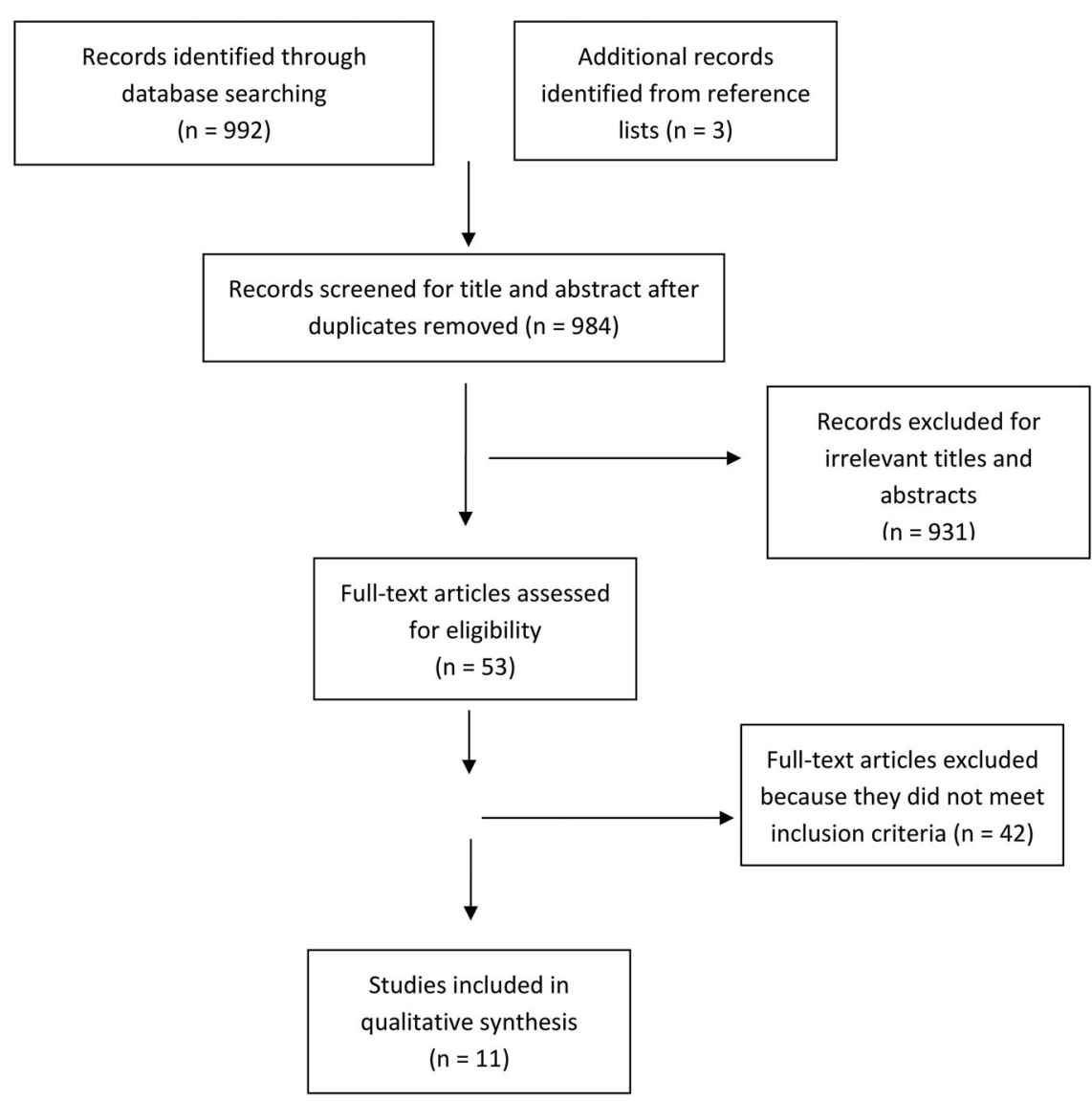

Figure 1. Flow chart of the study inclusion selection process.

types of bias. Across the domains, Sahota et al. (2001), Ha et al. (2015) and Meyer et al. (2014) were estimated to have the lowest risk of bias while an unclear risk of bias was estimated for the blinding of outcome assessment in almost all of the studies.

\section{Characteristics of the intervention studies}

The extracted information and the findings of the included studies are presented in Tables 3 and 4. All interventions included either physical activity only (three studies) or physical activity as part of a multicomponent or broader programme (eight studies). Four studies contained a nutrition component (Elinder et al., 2012; Gorely et al., 2009; Sahota et al., 2001; Stock et al., 2007), one study included educational advice to develop a healthy body image (Stock et al., 2007), while four interventions highlighted the importance of physical activity for health (Boyle-Holmes et al., 2010; Elinder et al., 2012; Gorely et al., 2009; Sahota et al., 2001). In addition, four of the interventions engaged the families through homework with a physical activity component (Gorely et al., 2009), through information leaflets (Gorely et al., 2009; McNeil et al., 2009; Sahota et al., 2001) and via parent information evenings (McNeil et al., 2009). Two interventions focused on modifying the 
Table 2. Summary of the estimated risk of bias for the 11 studies included.

\begin{tabular}{|c|c|c|c|c|c|c|c|}
\hline Study & $\begin{array}{c}\text { Random } \\
\text { sequence } \\
\text { generation }\end{array}$ & $\begin{array}{c}\text { Allocation } \\
\text { concealment }\end{array}$ & $\begin{array}{l}\text { Blinding of } \\
\text { participants and } \\
\text { personnel }\end{array}$ & $\begin{array}{l}\text { Blinding of } \\
\text { outcome } \\
\text { assessment }\end{array}$ & $\begin{array}{l}\text { Incomplete } \\
\text { outcome data }\end{array}$ & $\begin{array}{l}\text { Selective } \\
\text { reporting }\end{array}$ & $\begin{array}{c}\text { Other } \\
\text { bias }\end{array}$ \\
\hline $\begin{array}{l}\text { Hartmann et al. } \\
\text { (2010) }\end{array}$ & + & $?$ & $?$ & $?$ & $?$ & + & + \\
\hline $\begin{array}{l}\text { Gorely, Nevill, } \\
\text { Morris, Stensel, } \\
\text { and Nevill (2009) }\end{array}$ & - & - & $?$ & ? & + & + & + \\
\hline Sahota et al. (2001) & + & $?$ & - & $?$ & + & + & + \\
\hline Stock et al. (2007) & - & - & - & ? & - & + & + \\
\hline $\begin{array}{l}\text { Boyle-Holmes et al. } \\
\text { (2010) }\end{array}$ & - & - & - & $?$ & + & + & + \\
\hline $\begin{array}{l}\text { McNeil, Wilson, } \\
\text { Sliever, Ronca, } \\
\text { and Mah (2009) }\end{array}$ & $?$ & $?$ & - & ? & - & + & + \\
\hline $\begin{array}{l}\text { Elinder, Heinemans, } \\
\text { Hagberg, Quetel, } \\
\text { and Hagströmer } \\
\text { (2012) }\end{array}$ & - & - & - & ? & + & + & + \\
\hline $\begin{array}{l}\text { Hyndman, Benson, } \\
\text { Ullah, and Telford } \\
\text { (2014) }\end{array}$ & - & - & - & ? & + & + & + \\
\hline $\begin{array}{l}\text { Ha, Burnett, Sum, } \\
\text { Medic, and Ng } \\
\text { (2015) }\end{array}$ & + & $?$ & $?$ & ? & + & + & + \\
\hline Meyer et al. (2014) & + & $?$ & + & $?$ & + & + & + \\
\hline $\begin{array}{l}\text { Wood, Gladwell, and } \\
\text { Barton (2014) }\end{array}$ & - & - & - & $?$ & + & + & + \\
\hline
\end{tabular}

+: low risk of bias; ?: unclear risk of bias; -: high risk of bias.

playground area (Hyndman et al., 2014; Wood et al., 2014) while one study promoted skipping as physical activity (Ha et al., 2015).

Six of the interventions were randomised controlled trials (Table 3). The control groups engaged in their regular physical education classes for all interventions. Sample sizes varied greatly from a baseline total of 25 to 1464 children while the duration of the interventions ranged from five weeks up to two years. Finally, the frequency of the interventions was predominantly three times a week, with some interventions occurring twice a week or every day while others were flexible as to the teacher's/instructor's discretion. Two studies did not specify the frequency of the intervention (McNeil et al., 2009; Sahota et al., 2001).

\section{Assessment of wellbeing}

There were 13 different indicators of wellbeing assessed throughout the studies and 12 different measures used (see Table 4). Two studies used the Child Health Questionnaire (CHQ-PF50) of which one study used the parent proxy version of the questionnaire. Two studies used the Self-Perception Profile for Children (Harter, 1985), while three studies used the Perceived Competence Scale for Children (Harter, 1982).

\section{Assessment of physical activity}

Physical activity was assessed by objective or subjective tools (see Table 4). Six studies measured physical activity using objective measures - that is, accelerometers or pedometers. Five studies measured physical activity using self-report questionnaires. 
Table 3. Characteristics of the selected intervention studies.

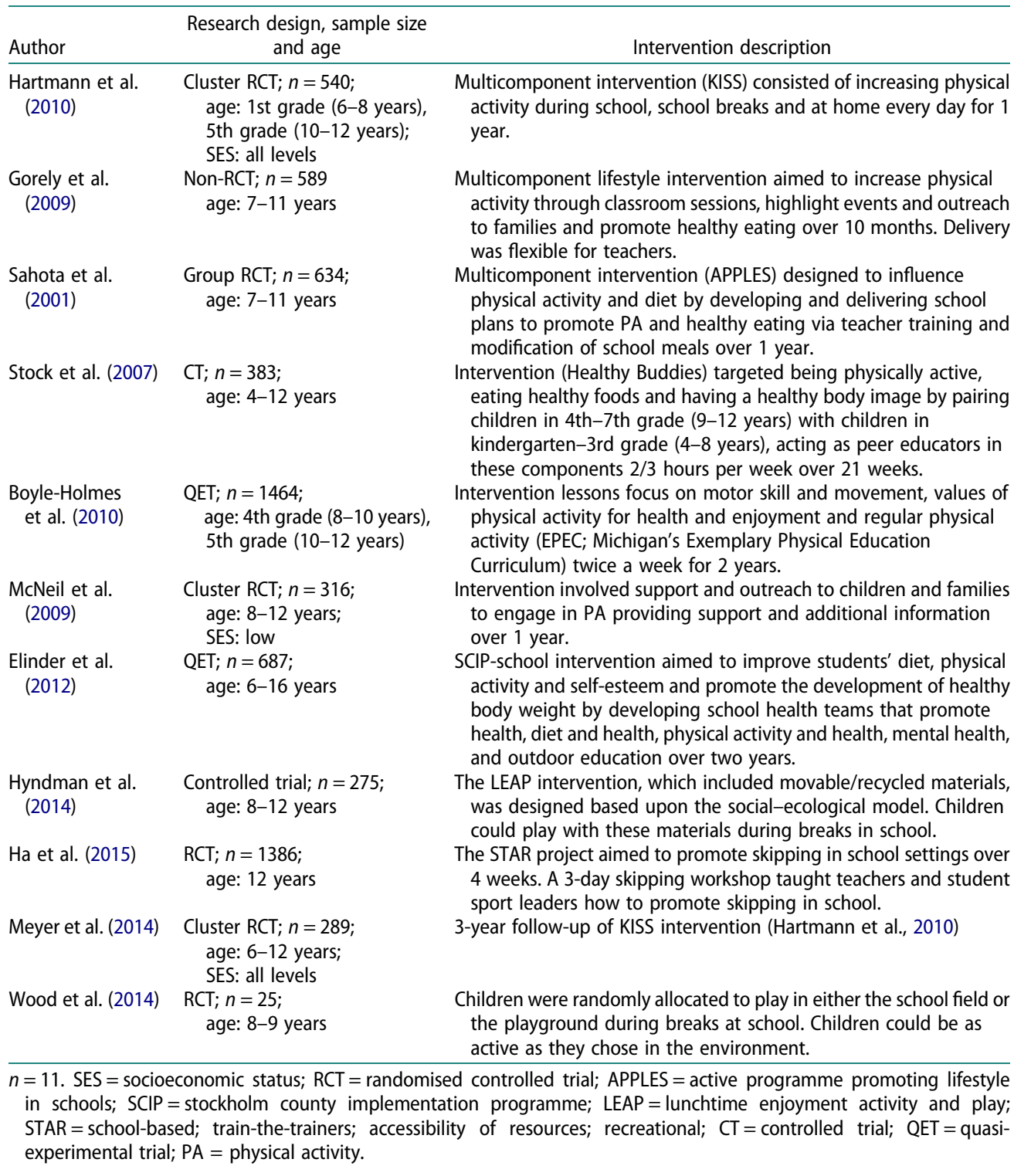

\section{Effect of interventions}

For eight of the 11 studies, the authors reported a significant intervention effect on physical activity (see Table 4). Five of the eight interventions used objective measures of physical activity while the remaining three used a questionnaire. Eight of the 11 studies reported no significant intervention effect on any wellbeing indicator (depicted as ' $n s^{\prime}$ in Table 4). In the APPLES study, the only significant difference in wellbeing variables was a small increase in global self-worth for obese children in the intervention group (Sahota et al., 2001). First-grade children of an intervention group produced a significant difference in their psychosocial quality of life scores post intervention $(p<.05)$ in 
Table 4. Results of included intervention studies examining significant effects on children's physical activity and wellbeing.

\begin{tabular}{|c|c|c|c|}
\hline Author & Measure of wellbeing & Physical activity measure & Main findings on physical activity \& wellbeing \\
\hline $\begin{array}{l}\text { Hartmann et al. } \\
(2010)\end{array}$ & $\begin{array}{l}\text { Physical and psychosocial } \\
\text { quality of life: CHQ-PF50 }\end{array}$ & $\begin{array}{l}\text { Accelerometer: Total PA, in school, out of school, total } \\
\text { MVPA, MVPA in school, MVPA out of school }\end{array}$ & $\begin{array}{l}\text { Total PA: } n \text { s. Total PA in school: I group significantly higher }(p<.005) \\
\text { Total PA out of school: } n s \text {. Total MVPA: I group significantly higher }(p<.05) \text {; total } \\
\text { MVPA in school: I group significantly higher }(p<.001) \text {; total MVPA out of school: } \\
n s \\
\text { 1st graders: Psychosocial QoL: I significant effect }(p<.05) \\
\text { 1st and 5th graders: Physical QoL: } n s \\
\text { 5th graders: Psychosocial QoL: } n s\end{array}$ \\
\hline $\begin{array}{l}\text { Gorely et al. } \\
\text { (2009) }\end{array}$ & $\begin{array}{l}\text { Perceived physical self- } \\
\text { competence: PSPP-C }\end{array}$ & $\begin{array}{l}\text { PA: all participants wore a pedometer. } \\
50 \% \text { of children wore an Actigraph accelerometer for a } \\
\text { week pre/post to assess MVPA }\end{array}$ & $\begin{array}{l}\text { PA (pedometer): I significantly increased number of steps in comparison to control } \\
\text { ( } p<.001) \\
\text { PA (accelerometer): I significant increase in MVPA compared to control. } \\
\text { Perceived physical self-competence: } n s\end{array}$ \\
\hline $\begin{array}{l}\text { Boyle-Holmes } \\
\text { et al. (2010) }\end{array}$ & $\begin{array}{l}\text { Perceived physical activity } \\
\text { competence : PCS }\end{array}$ & $\begin{array}{l}\text { Self-report measure of physical activity: Self- } \\
\text { Administered Physical Activity Checklist } \\
\text { (SAPAC) }\end{array}$ & $\begin{array}{l}\text { Perceived physical activity competence: } n s \\
\text { PA: 4th grade I PA levels significant increase compared to control }(p<.01) \\
\text { PA: 5th grade: } n s\end{array}$ \\
\hline $\begin{array}{l}\text { McNeil et al. } \\
\text { (2009) }\end{array}$ & $\begin{array}{l}\text { Self-esteem: Self-Esteem Index } \\
\text { (SEl) }\end{array}$ & $\begin{array}{l}\text { Self-report measure of physical activity: The Children's } \\
\text { Assessment of Participation and Enjoyment (CAPE) }\end{array}$ & $\begin{array}{l}\text { Self-esteem: } n s \\
\text { PA: I twice as likely to increase PA compared to control group (RR 2.1, } p=.23 \text { ) }\end{array}$ \\
\hline $\begin{array}{l}\text { Elinder et al. } \\
\text { (2012) }\end{array}$ & $\begin{array}{l}\text { Global self-worth: the Global } \\
\text { Self-Worth subscale of Harter's } \\
\text { Self-Perception Profile } \\
\text { Wellbeing: questionnaire }\end{array}$ & Self-report measure of physical activity: questionnaire & $\begin{array}{l}\text { PA: } n \text { s } \\
\text { Global self-worth: } n s \\
\text { Wellbeing: } n s\end{array}$ \\
\hline
\end{tabular}


Table 4. Continued.

Author

Hyndman et al. Physical activity measure

Main findings on physical activity \& wellbeing life

Psychosocial scale quality of life Overall quality of life: PEDS QL 4.0

Ha et al. (2015)

HRQOL: KIDSCREEN-27

Physical and psychosocial

Meyer et al.

(2014)

Wood et al. (2014)
Objective measure of PA: pedometer

Moderate and vigorous physical activity: direct observation
Objective measure of PA: Actigraph Accelerometer (mean minutes in MVPA)

Accelerometer: Total PA, total moderate-to-vigorous physical activity (MVPA)

\section{measurement of PA (time spent in MVPA):}

Pedometer: I group significantly greater mean steps per minute than the control school $(p<.001)$

I group significantly greater distance per minute than the control school $(p<.001)$ Moderate activity: $n s$

Vigorous activity: I group significantly higher than the control school $(p<.001)$ Physical health scale quality of life: $n$

Psychosocial scale quality of life: $n$

Overall quality of life: $n s$

MVPA: C group had higher levels MVPA than the I group.

Physical Wellbeing: $n s$

Psychological Wellbeing: $n s$

Autonomy \& Parent Relation: Group difference: I higher than control group ( $p$ $<.05)$

Peers \& Social Support: $n s$

School Environment: $n s$

PA: $n s$

Physical QoL: $n$ s

Psychosocial QoL: ns

MVPA: Field MVPA significantly greater than playground MVPA $(p<.001)$ Self-esteem: $n s$ for Children; FRS = Figural Rating scale; SEI = Self-esteem Index; PEDS QL = Paediatric Quality of Life Inventory 4; HRQOL = Health Related Quality of Life. 
comparison to the control group following a one-year physical activity intervention, while the fifth-grade children reported no significant difference (Hartmann et al., 2010). An intervention group reported higher levels of autonomy and parent relationships post intervention following a school-based intervention promoting skipping to children (mean age $=12$ years; $\mathrm{Ha}$ et al., 2015). Although significant changes were found for physical and cognitive competence subscale scores for children in the Healthy Buddies study, these were for both the intervention and control groups. No significant changes could be attributed to the intervention (Stock et al., 2007).

From the three interventions that reported significant intervention effects on a wellbeing indicator, one study reported a significant increase in physical activity for the intervention group (Hartmann et al., 2010), one study reported no significant interaction effect (Sahota et al., 2001), while one study unexpectedly found a significant increase in physical activity in the control group in comparison to the intervention group (Ha et al., 2015).

\section{Discussion}

The purpose of this review was to investigate the effect of school-based physical activity interventions on children's physical activity levels and their wellbeing, taking into consideration the measurement of wellbeing and physical activity. In all, 11 school-based physical activity interventions that assessed an aspect of wellbeing on primary school children were found. From these, three studies reported a significant positive effect on an indicator of wellbeing while eight studies reported no statistically significant effect. Furthermore, eight studies reported a significant increase in physical activity while three studies reported no significant effect. There was considerable heterogeneity in the measures of wellbeing used, and no specific types of wellbeing variables were more positively affected by the interventions than other wellbeing variables.

The school-based physical activity interventions in this review aimed at increasing physical activity by incorporating any aerobic activity, exercise, physical education or physical training component into an intervention. Although eight of the 11 studies reported a significant increase in physical activity, only one of those studies reported a significant increase in an indicator of wellbeing (Hartmann et al., 2010). Unexpectedly, Ha et al. (2015) found that the control group had significantly higher physical activity than the intervention group following the intervention. As students in the control group had greater levels of physical activity at baseline, it was suggested that the control group were much more active in general, even after adjusting for baseline values ( $\mathrm{Ha}$ et al., 2015). Despite the control group achieving greater physical activity levels, a main effect for group for the Autonomy and Parent relation subscale was found for children in the intervention group who scored higher than the control group (Ha et al., 2015). This finding suggests that the Autonomy and Parent subscale may not be affected by increased levels of physical activity. However, as physical activity was only measured during school hours it is unclear whether the intervention group were more active outside of school, which may have had an effect on the wellbeing indicator.

Improvements in wellbeing were found in two studies where the child's wellbeing at baseline may have been considered low. Sahota et al. (2001) reported a small increase in global self-worth for obese children but not children of healthy weight in the intervention schools, while a significant effect on psychosocial wellbeing was found in overweight 
first-grade children (Hartmann et al., 2010). These findings support previous research on overweight and sedentary children following separate after-school and hospital-based physical activity interventions (Kemp \& Pienaar, 2010; Petty, Davis, Tkacz, Young-Hyman, $\&$ Waller, 2009). Previous research highlighted a negative relationship between overweight/obesity and aspects of a child's wellbeing such as self-perceptions of social acceptance and physical appearance (McCullough, Muldoon, \& Dempster, 2009; Ottova, Erhart, Rajmil, Dettenborn-Betz, \& Ravens-Sieberer, 2012). Therefore, it is possible that overweight/obese children could have lower levels of wellbeing at baseline and could benefit more from the intervention than children whose levels of wellbeing were already high.

For the seven studies that significantly increased physical activity in the intervention group, five of these are multicomponent studies. This is in line with the review by Kriemler et al. (2011) who also found that multicomponent school-based physical activity interventions were more successful at increasing physical activity. Interestingly, interventions that included wellbeing components would expect to show positive intervention effects but non-significant results were reported. The Healthy Buddies intervention contained a component on healthy body image but found no significant differences between the intervention and control groups (Stock et al., 2007). A suggested reason for this was a potential ceiling effect for the baseline wellbeing scores of this middle-class population, while it was also suggested that the sample size was too small to determine whether those with extreme scores had benefited from the intervention (Stock et al., 2007). Similarly, Elinder et al. (2012) included a component on mental health and suggested that the lack of effects might be caused by low implementation of the component by the school, by the information not being comprehensive enough or that the effects may have worn off after two years (post-measures).

The mixed findings on wellbeing reported from the studies included in this review may be attributed to the inconsistent measurement of child wellbeing. A previous systematic review of child wellbeing also observed that child wellbeing was inconsistently measured (Pollard \& Lee, 2003). This is in line with Biddle and Asare (2011) who suggested that measurement inconsistencies may contribute to the weak physical activity and mental health relationship in children. In the current review, many of the studies used narrow measures of wellbeing, such as self-perception, which is consistent with Biddle and Asare (2011) who observed that research in this field has focused on depression, anxiety and self-esteem. However such approaches have been criticised for not capturing the multidimensional nature of wellbeing, with Pollard and Lee (2003) calling this 'bait and switch' tactics, whereby wellbeing is mentioned in the title of the article yet only a single domain of wellbeing is assessed and if so with primarily deficit indicators. Furthermore, as researchers chose which aspects of wellbeing to measure, it is likely that the indicators chosen may not fully reflect how a child perceives their own wellbeing. Some differences between children's and adults' views of child wellbeing have been reported in one study (Sixsmith, Nic Gabhainn, Fleming, \& O'Higgins, 2007). Furthermore, children as young as seven years old consider wellbeing a multidimensional concept that includes feelings of both sadness and happiness (Fattore, Mason, \& Watson, 2007; Nic Gabhainn \& Sixsmith, 2005), mirroring Diener's (1984) definition of wellbeing. This is in contrast to the narrow focus of indicators used in the school-based interventions. Hence, the measures of wellbeing chosen in the reviewed interventions may not best reflect a child's wellbeing. 
Therefore, it is not inconceivable to consider that the mixed results on wellbeing found in this review may be because a measure based on the child's view was not used and that adopting the use of such a measure that is more valid and reliable will yield more accurate intervention effects on wellbeing.

In addition, the measure of physical activity used may have also had an impact on the findings. Five of the 11 studies used a self-report measure of physical activity, of which three reported a significant increase in physical activity but no significant effect on wellbeing. As self-report measures are prone to error and recall bias due to the sporadic nature of children's movement and their difficulty remembering when and how intense their activity was (Baquet, Stratton, van Praagh, \& Berthoin, 2007; Chinapaw et al., 2010), the use of an objective measure of physical activity, such as an accelerometer, may provide a clearer understanding of the effects. However, five of the studies that reported a significant increase in physical activity used objective measures, with only one study reporting a positive effect on wellbeing. Clearly, the effects of school-based physical activity interventions on wellbeing are complex, and both the measures of wellbeing and physical activity should be considered when determining the effects.

Many of the studies had a high risk of bias in the domains of random sequence generation, allocation concealment and blinding of participants and personnel. Six of the 11 studies were RCTs, and only four of them described the process and were considered a low risk of bias. As RCTs are considered a high level of evidence, such bias may affect the outcome of the intervention. Randomisation can be challenging when using schools due to possible contamination of intervention information across classes and groups within or across schools close together. High risk of bias in allocation concealment and blinding of participants and personnel could attenuate the effects of the intervention, suggesting that the effects could be greater. Therefore, the risk of bias results must be considered when determining the effect of the interventions on child wellbeing.

As the concept of wellbeing is multidimensional and open to interpretation, it was not possible to include all of the constructs that may be considered applicable. The exclusion of non-journal articles, dissertation abstracts and studies not in English may have also lost potential studies. Due to the small number of studies and large heterogeneity in terms of intervention, sample size and measurement of wellbeing across the studies, it was not possible to conduct a meta-analysis. The method for study extraction and risk of bias would have been further enhanced by including a second researcher along with calculation of the inter-rater reliability of the researchers. However, the inclusion of various positive search terms along with negative search terms of wellbeing will have contributed to an extensive search, and assessing the effect of interventions on both physical activity and wellbeing and their measurement tools enabled an extensive and novel review of this important area of research.

\section{Conclusion}

From an initial search of 995 studies, 11 were reviewed showing mixed findings for the effect of physical activity on children's wellbeing in school settings. Methodological inconsistencies were found in both the measurement of wellbeing and that of physical activity. We recommend that future studies incorporate a measure of child wellbeing based on 
children's perceptions and that physical activity be measured objectively in order for the links between physical activity and wellbeing to be determined for children.

\section{Disclosure statement}

No potential conflict of interest was reported by the authors.

\section{ORCID}

David Hassan (D) http://orcid.org/0000-0003-0261-376X

\section{References}

Ahn, S., \& Fedewa, A. L. (2011). A Meta-analysis of the relationship between children's physical activity and mental health. Journal of Pediatric Psychology, 36(4), 385-397. doi:10.1093/jpepsy/jsq107

Baquet, G., Stratton, G., van Praagh, E., \& Berthoin, S. (2007). Improving physical activity assessment in prepubertal children with high-frequency accelerometry monitoring: a methodological issue. Preventive Medicine, 44(2), 143-147. doi:10.1016/j.ypmed.2006.10.004

Biddle, S. J. H., \& Asare, M. (2011). Physical activity and mental health in children and adolescents: a review of reviews. British Journal of Sports Medicine, 45, 886-895.

Biddle, S. J. H., Fox, K. R., \& Boutcher, S. H. (2000). Physical activity and psychological well-being. London: Routledge.

Biddle, S. J. H., O'Connell, S., \& Braithwaite, R. E. (2011). Sedentary behaviour interventions in young people: a meta-analysis. British Journal of Sports Medicine, 45, 937-942. doi:10.1136/bjsports-2011090205

Boyle-Holmes, T., Grost, L., Russell, L., Laris, B. A., Robin, L., \& Haller, E., ... Lee, S. (2010). Promoting elementary physical education: Results of a school-based evaluation study. Health Education \& Behavior, 37(3), 377-389.

Breslin, G., Gossrau-Breen, D., McCay, N., Gilmore, G., MacDonald, L., \& Hanna, D. (2012). Physical activity, gender, weight status, and wellbeing in 9- to 11-year-old children: A cross-sectional survey. Journal of Physical Activity and Health, 9, 394-401.

Cameron, D. (2010). PM speech on well-being: A transcript of a speech given by the Prime Minister on well-being on 25 November 2010. Number10.gov.uk The Official site of the Prime Minister. Retrieved from http://www.number10.gov.uk/news/speeches-and-transcripts/2010/11/pmspeech-on-well-being-57569

Casperson, C. J., Powell, K. E., \& Christenson, G. M. (1985). Physical activity, exercise, and physical fitness: definitions and distinctions for health-related research. Public Health Reports, 100(2), 126-131. Retrieved from http://www.ncbi.nlm.nih.gov/pmc/articles/PMC1424733/

Cheung, S. Y., Mak, J. Y., \& Chan, J. (2008). Children's physical activity participation and psychological wellbeing. Research Quarterly for Exercise and Sport, 79(Suppl. 1), A30.

Chinapaw, M. J. M., Mokkink, L. B., van Poppel, M. N. M., van Mechelen, W., \& Terwee, C. B. (2010). Physical activity questionnaires for youth: A systematic review of measurement properties. Sports Medicine, 40(7), 539-563. doi:10.2165/11530770-000000000-00000

Department of Health, Physical Activity, Health Improvement and Protection. (2011). Start active, stay active: A report on physical activity from the four home countries' Chief Medical Officers. Retrieved from http://www.dh.gov.uk/prod_consum_dh/groups/dh_digitalassets/documents/digitalasset/ dh_128210.pdf

Diener, E. (1984). Subjective well-being. Psychological Bulletin, 95(3), 542-575.

Ekeland, E., Heian, F., \& Hagen, K. B. (2005). Can exercise improve self-esteem in children and young people? A systematic review of randomised controlled trials. British Journal of Sports Medicine, 39 (11), 792-798.

Elinder, L. S., Heinemans, N., Hagberg, J., Quetel, A., \& Hagströmer, M. (2012). A participatory and capacity-building approach to healthy eating and physical activity - SCIP-school: a 2-year 
controlled trial. International Journal of Behavioral Nutrition and Physical Activity, 9, 145. Retrieved from http://www.ijbnpa.org/content/9/1/145

Fattore, T., Mason, J., \& Watson, E. (2007). Children's conceptualisation(s) of their well-being. Social Indicators Research, 80, 5-29.

Fox, K. R., Cooper, A., \& McKenna, J. (2004). The school and promotion of children's health enhancing physical activity: perspectives from the United Kingdom. Journal of Teaching Physical Education, 23 (4), 338-358.

Friedli, L. (2009). Mental health, resilience and inequalities. Denmark: World Health Organisation. Retrieved from http://www.euro.who.int/data/assets/pdf_file/0012/100821/E92227.pdf

Gorely, T., Nevill, M. E., Morris, J. G., Stensel, D. J., \& Nevill, A. (2009). Effect of a school-based intervention to promote healthy lifestyles in 7-11 year old children. International Journal of Behavioural Nutrition and Physical Activity, 6(5). doi:10.1186/1479-5868-6-5

Ha, A. S., Burnett, A., Sum, R., Medic, N., \& Ng, J. Y. Y. (2015). Outcomes of the rope skipping 'star' programme for schoolchildren. Journal of Human Kinetics, 45, 233-240. doi:10.1515/hukin-2015-0024

Harris, K. C., Kuramoto, L. K., Schulzer, M., \& Retallack, J. E. (2009). Effect of school-based physical activity interventions on body mass index in children: a meta-analysis. Canadian Medical Association Journal, 180, 719-726. doi:10.1503/cmaj.080966

Harter, S. (1982). The Perceived Competence Scale for Children. Child Development, 53(1), 87-97.

Harter, S. (1985). Manual for the self-perception profile for children. Denver, CO: University of Denver.

Hartmann, T., Zahner, L., \& Puhse, U. (2010). Effects of a school-based physical activity program on physical and psychosocial quality of life in elementary school children: A cluster randomized trial. Pediatric Exercise Science, 22(4), 511-522.

Higgins, J. P. T., Altman, D. G., \& Sterne, J. A. C. (2011). Assessing risk of bias in included studies. In J. P. T. Higgins \& S. Green (Eds.), Cochrane handbook for systematic reviews of interventions. Version 5.1.0. The Cochrane Collaboration, 2011. Retrieved from http://handbook.cochrane.org/

Huppert, F. A., \& Whittington, J. E. (2003). Evidence for the independence of positive and negative well-being: implications for quality of life assessment. British Journal of Health Psychology, 8(1), 107-122.

Hyndman, B. P., Benson, A. C., Ullah, S., \& Telford, A. (2014). Evaluating the effects of the Lunchtime Enjoyment Activity and Play (LEAP) school playground intervention on children's quality of life, enjoyment and participation in physical activity. BMC Public Health, 14, 164. doi:10.1186/14712458-14-164.

Kemp, C., \& Pienaar, A. E. (2010). The effect of a physical activity, diet and behaviour modification intervention on the self-perception of 9 to 12 year old overweight and obese children. African Journal for Physical, Health Education, Recreation and Dance, 16(1), 101-116. Retrieved from http://www.nwu.ac.za/files/images/Article4_2010_The.pdf

Kriemler, S., Meyer, U., Martin, E., van Sluijs, E. M. F., Andersen, L. B., \& Martin, B. W. (2011). Effect of school-based interventions on physical activity and fitness in children and adolescents: a review of reviews and systematic update. British Journal of Sports Medicine, 45(11), 923-930. doi:10.1136/ bjsports-2011-090186

Larun, L., Nordheim, L. V., Ekeland, E., Hagen, K. B., \& Heian, F. (2006). Exercise in prevention and treatment of anxiety and depression among children and young people. Cochrane Database Systematic Review, 19(3), CD004691. Retrieved from http://www.ncbi.nlm.nih.gov/pubmed/16856055

Mattocks, C., Ness, A., Leary, S., Tilling, K., Shield, J., Deere, K., ... Riddoch, C. (2008). Use of accelerometers in a large field-based study of children: protocols, design issues, and effects on precision. Journal of Physical Activity \& Health, 5(Suppl 1), s98-s111.

McCullough, N., Muldoon, O., \& Dempster, M. (2009). Self-perception in overweight and obese children: a cross-sectional study. Child: Care, Health and Development, 35(3), 357-364. doi:10.1111/j. 1365-2214.2008.00924.x

McNeil, D. A., Wilson, B. N., Sliever, J. E., Ronca, M., \& Mah, J. K. (2009). Connecting children to recreational activities: results of a cluster randomised trial. American Journal of Health Promotion, 23(6), 376-387. doi:10.4278/ajhp.071010107 
Meyer, U., Schindler, C., Zahner, L., Ernst, D., Hebestreit, H., ... Kriemler, S. (2014). Long-term effect of a school-based physical activity program (kiss) on fitness and adiposity in children: a cluster-randomized controlled trial. PLoS ONE, 9(2), e87929. doi:10.1371/journal.pone.0087929

Moher, D., Shamseer, L., Clarke, M., Ghersi, D., Liberati, A., Petticrew, M., Shekelle, P., Stewart, L. A., \& PRISMA-P Group. (2015). Preferred reporting items for systematic review and meta-analysis protocols (PRISMA-P) 2015 statement. Systematic Reviews, 4(1), 1. doi:10.1186/2046-4053-4-1

Nic Gabhainn, S., \& Sixsmith, J. (2005). Children's understandings of wellbeing. Dublin: The National Children's Office. Retrieved from http://www.nuigalway.ie/hbsc/documents/childrenunderstan dingofwellbeing.pdf

Ottova, V., Erhart, M., Rajmil, L., Dettenborn-Betz, L., \& Ravens-Sieberer, U. (2012). Overweight and its impact on the health-related quality of life in children and adolescents: results from the European KIDSCREEN survey. Quality of Life Research, 21, 59-69. doi:10.1007/s11136-011-9922-7

Parfitt, G., \& Eston, R. G. (2005). The relationship between children's habitual activity level and psychological well-being. Acta Paediatrica, 94(12), 1791-1797.

Parfitt, G., Pavey, T., \& Rowlands, A. V. (2009). Children's physical activity and psychological health: the relevance of intensity. Acta Paediatrica, 98(6), 1037-1043.

Park, N. (2004). The role of subjective well-being in positive youth development. The ANNALS of the American Academy of Political and Social Science, 591(1), 25-39. doi:10.1177/0002716203260078

Petty, K. H., Davis, C. L., Tkacz, J., Young-Hyman, D., \& Waller, J. L. (2009). Exercise effects on depressive symptoms and self-worth in overweight children: a randomized controlled trial. Journal of Pediatric Psychology, 34(9), 929-39.

Pollard, E. L., \& Lee, P. D. (2003). Child well-being: a systematic review of the literature. Social Indicators Research, 61, 59-78. doi:10.1023/A\%3A1021284215801

Rees, G., Bradshaw, J., Goswami, H., \& Keung, A. (2010). Understanding children's well-being: A national survey of young people's well-being. London: The Children's Society.

Sahota, P., Rudolf, M. C. J., Dixey, R., Hill, A. J., Barth, J. H., \& Cade, J. (2001). Randomised controlled trial of primary school based intervention to reduce risk factors for obesity. British Medical Journal, 323, 1-5. doi:10.1136/bmj.323.7320.1029

Sanchez-Lopez, M., Salcedo-Aguilar, F., Solera-Martınez, M., Moya-Martınez, P., Notario-Pacheco, B., \& Martınez-Vizcaıno, V. (2009). Physical activity and quality of life in schoolchildren aged 11-13 years of Cuenca, Spain. Scandinavian Journal of Medicine and Science in Sports, 19(6), 879-884. doi:10.1111/j.1600-0838.2008.00839.x

Sixsmith, J., Nic Gabhainn, S., Fleming, C., \& O'Higgins, S. (2007). Childrens', parents' and teachers' perceptions of child wellbeing. Health Education, 107(6), 511-523.

Stock, S., Miranda, C., Evans, S., Plessis, S., Ridley, J., Yeh, S., \& Chanoine, J. P. (2007). Healthy Buddies: a novel, peer-led health promotion program for the prevention of obesity and eating disorders in children in elementary school. Pediatrics, 120(4), e1059-e1068.

Tomson, L. M., Pangrazi, R. P., Friedman, G., \& Hutchinson, N. (2003). Childhood depressive symptoms, physical activity and health related fitness. Journal of Sport and Exercise Psychology, 25(4), 419-439.

UNICEF Office of Research. (2013). Child well-being in rich countries: A comparative overview. Innocenti Report Card 11. Florence: UNICEF Innocenti Research Centre.

Verloigne, M., Van Lippevelde, W., Maes, L., Yıldırım, M., Chinapaw, M., \& Manios, Y. (2012). Levels of physical activity and sedentary time among 10- to 12-year-old boys and girls across 5 European countries using accelerometers: an observational study within the ENERGY-project. International Journal of Behavioral Nutrition and Physical Activity, 9, 34. doi:10.1186/1479-5868-9-34

van Wijnen, L. G. C., Wendel-Vos, G. C. W., Wammes B. M., \& Bemelmans W. J. E. (2009). The impact of school-based prevention of overweight on psychosocial well-being of children. Obesity Reviews, 10 (3), 298-312. doi:10.1111/j.1467-789X.2008.00549.x

Wood, C., Gladwell, V., Barton, J. (2014). A repeated measures experiment of school playing environment to increase physical activity and enhance self-esteem in UK school children. PLOS ONE, 9(9), e108701. doi:10.1371/journal.pone.0108701

World Health Organisation. (2006). Basic documents constitution of the world health organisation (45th ed.). Geneva: World Health Organisation. Retrieved from http://www.who.int/governance/eb/ who_constitution_en.pdf 